\title{
Policy consequences of direct legislation theory, empirical models and evidence
}

\author{
Simon Hug
}

Published online: 15 March 2010

(C) Springer Science+Business Media B.V. 2010

\begin{abstract}
Most theoretical models predict that institutions allowing for direct legislation should lead, on average, to policies more closely reflecting the wishes of the voters. While some agreement exists at the theoretical level about the expected policy consequences of direct legislation, empirical evidence has been scant so far. In this paper I discuss the reasons for this scantiness of empirical evidence, namely the intricacies of the adequate empirical model to test the theoretical proposition, and suggest possible solutions to this problem. Re-analyzing a dataset with which some authors have found no evidence in support of the theoretical claim, I show that with a better adapted empirical model we find results in synch with our theoretical expectations. Thus, policies in states that allow for direct legislation reflect on average more closely the voters' wishes. Using Monte-Carlo simulations I also demonstrate the properties of the proposed estimator and suggest that it could be used in other contexts, like when assessing the responsiveness of legislators.
\end{abstract}

Keywords Direct legislation · Referendums · Policy effects · Switching regression · US states

\section{Introduction}

Most research on direct legislation suggests that allowing voters to vote directly on policies should affect policy outcomes (see Lupia and Matsusaka 2004 for an incisive review of the literature). Scholars employing game-theoretic models to assess these effects have mostly found that the policy outcomes should reflect more closely the median voter's

Earlier versions of this paper was presented at the Annual meeting of the Public Choice Society, San Antonio, March 8-11, 2001 and at seminars at Texas A\&M University, Ohio State University, the University of St. Gallen and the University of Montreal.

S. Hug $(\varangle)$

Département de Science Politique, Faculté des Sciences Économiques et Sociales,

Université de Genève, 40 Bd du Pont d'Arve, 1211 Geneva 4, Switzerland

e-mail: simon.hug@unige.ch 
preferences. ${ }^{1}$ Empirical studies have so far, however, had difficulty demonstrating this effect convincingly. The reason for this is that many empirical studies employ model specifications which either yield biased estimates of the effect of direct legislation and/or do not allow for assessing whether the policy is affected in the direction of the median voter's preferences (see Matsusaka's 2001 discussion).

Consequently, I propose in this paper an empirical model, which derives directly from the theoretically implied predictions on the effect of direct legislation. While the model is based on a simplifying assumption, its empirical evaluation yields largely results in support of the theoretical implications on the effect of direct legislation. In Monte Carlo simulations I also demonstrate that except under very specific conditions, the proposed empirical model yields improved estimates than a simple OLS regression with a dummy indicator for direct legislation states.

The paper proceeds as follows. In Sect.2, I briefly review the literature on the policy effects of direct legislation. In Sect. 3, I present first the theoretically implied empirical model, before discussing specifications that have been employed in the literature. I demonstrate that almost all of these specifications are based on erroneous assumptions which inevitably result in biases in the estimated coefficients of relevance. In Sect. 4, I present the results of Monte Carlo simulations of the proposed empirical model for two setups. These simulations demonstrate that the proposed empirical model provides better estimates and more information on the effect of direct legislation. In Sect. 5, I employ the proposed empirical model to assess the effect of direct legislation using a dataset on the US states used by Lascher et al. (1996). I demonstrate that with a more appropriate empirical model we find, contrary to these authors, direct legislation effects for several policies, which are in accordance with predictions from theoretical models. Section 6 summarizes these results and suggests that the proposed empirical model is also applicable in other research areas, for instance when studying the responsiveness of legislators in different institutional contexts.

\section{The policy effects of direct legislation}

There is a large consensus in the literature that institutions for direct legislation affect policy outcomes. ${ }^{2}$ Only few authors, like for instance Cronin (1989, p. 232), argue that policies do not differ between political entities allowing for direct legislation and those that do not. From the early incisive writings of Key and Crouch (1939), which were largely ignored by subsequent authors, it also seemed clear that the policy effects of direct legislation may be of two different sorts. First, the policy effects may be direct, in the sense that policies are adopted by voters, which would have failed in the normal legislative process. Second, institutions allowing for direct legislation may have indirect effects when the legislature adopts policies which it would not have adopted without the presence these institutions. Often such indirect effects emerge when interested groups threaten legislatures with their own proposals, which they might try to realize through direct legislation. ${ }^{3}$

\footnotetext{
1 Obviously, the notion of median voter only applies in contexts where the policy outcome reflects a onedimensional policy space. Tsebelis (2000) and Hug and Tsebelis (2002) propose ways in which the general theoretical ideas discussed in this paper apply in multidimensional spaces.

2 Gerber and Hug (2001) discuss in much more detail the issues involved in this question.

3 Matsusaka (2000, p. 658) adds a possible signaling effect, namely when “...election returns from initiative contests...convey information to representatives about citizen preferences that they later incorporate into policy."
} 
These two types of effects appear especially clearly in recent theoretical work. Steunenberg (1992), Gerber (1996, 1999), Moser (1996), Besley and Coate (2001), Matsusaka and McCarty (2001), Hug and Tsebelis (2002) and Hug (2004) all show that the overall consequences of direct legislation comprise both direct and indirect effects. ${ }^{4}$ From these theoretical models two other important elements transpire. First, based on their theoretical implications it appears clearly that sorting out direct from indirect effects empirically is difficult. This, because these two effects interact and thus form the result of a strategic interplay among various actors. Second, the theoretical models also demonstrate that the policy effect of direct legislation, whether direct or indirect, is dependent on at least the preferences of the legislature and the voters. ${ }^{5}$ The general thrust of the theoretical results is that under most conditions, policies adopted under direct legislation will be biased toward the preferences of the median voter. ${ }^{6}$ For example, if the legislature would like to spend $\$ 1$ million on a school building but the voters prefer spending $\$ 2$ million, then direct legislation will, on average, lead to higher expenditures. Conversely, if the same legislature is on a spending spree and wishes to construct a school-palace for $\$ 10$ million, direct legislation will lead to policies closer to the preferred spending level of the frugal voters. Consequently, in one case direct legislation will lead to higher expenditures, while in the other expenditures will be lower, due to direct citizen-lawmaking. This shows that the effect of direct legislation is contingent on the preference configurations of the most important actors, namely voters and the legislature.

In summary, the theoretical literature suggests that institutions for direct legislation have both direct and indirect effects, but that these two types of effects are difficult to separate empirically. In addition, the direction of these effects is dependent on the voters' preferences, in the sense that policies will reflect more closely these preferences under direct legislation than in the absence of these institutions.

\section{Theory and empirical models}

Strictly speaking the theoretical models mentioned above imply an empirical model of the following type ${ }^{7}$ :

$$
\left|Y_{i}-X_{m_{i}}\right|=f\left(X_{i}\right)
$$

\footnotetext{
4 Strictly speaking, the complete information models of Steunenberg (1992) and Gerber $(1996,1999)$ do not cover both types of effects. In Steunenberg's (1992) model initiatives always occur if the status quo is different from the voters' preferences, which implies that only direct effects are considered. In Gerber $(1996,1999)$ model votes never occur in equilibrium, since the legislature anticipates voter and interest group reactions. Thus, the predicted policy effects are only of the indirect nature.

5 Most models comprise also an interest group or an opposition, which triggers direct legislation. Given that various such groups may fulfill this role, their preferences will empirically be of less relevance.

6 It has to be noted that two models find that under very specific conditions, voters may be worse off under direct legislation. Matsusaka and McCarty (2001) show that if the legislature attempts to be a perfect agent of the voters, without knowing the latter's preferences, it may try to preempt ballot measures by adopting policies, which are detrimental for the voters. This occurs, however, only if the legislature wishes to buy off an extreme interest group. Similarly, Hug (2004) also finds that if the legislature's and the voters' interest are close, direct legislation may lead to policies less preferred by the voters, because the legislature wishes to avoid ballot measures. In both models, however, this detrimental effect is dependent on the voters' preferences. For instance Proposition 3 in Matsusaka and McCarty (2001) states that policy outcomes may be more extreme under direct legislation, where "extremeness" is implicitly defined by the distance between the adopted policy and the expected value of the voters' preferences. Thus, both positive and negative effects of direct legislation from the perspective of voters are contingent on the latter's preferences.

7 Matsusaka (2001) suggests using the square of the differences, which would make deriving an estimator more complicated. The gist of the argument is, however, the same.
} 
where $Y_{i}$ is a measure of a particular policy adopted in entity $i, X_{m_{i}}$ is the median voter's preferred policy in this area, ${ }^{8}$ and $X_{i}$ contains an indicator variable for the presence of direct legislation $d l_{i}$ and possibly additional control variables. If we had direct measures for both $Y$ and $X_{m}$ on the same scale, for instance how much money is being spent for schools and how much money the median voter wants to spend on schools, we could directly estimate Eq. 1. With the possible exception of Gerber's (1996) study on teenage abortions, we almost never have data on the median voter's preferences on the same scale as our measure for the policy outcome. ${ }^{9}$ To see this problem it is useful to reformulate Eq. 1 in the following way:

$$
\begin{gathered}
\text { if } Y_{i}-X_{m_{i}}>0, \quad Y_{i}=f\left(X_{i}\right)+X_{m_{i}} \\
\text { if } Y_{i}-X_{m_{i}} \leq 0, \quad Y_{i}=-f\left(X_{i}\right)+X_{m_{i}}
\end{gathered}
$$

In this setting it becomes clear that in the absence of a perfect measure of what the median voter wants (e.g., what amount of money) we cannot estimate Eq. 1 (or the system of Eq. 2 for that matter). Thus, if we have to estimate $X_{m_{i}}$ with proxies (like the often used conservative-liberal scale), we cannot derive Eq. 2 directly from Eq. 1 . We may presume that $X_{m_{i}}$ is related to an array of variables $P_{i}$ presumably linked to the preferences of the median voter:

$$
X_{m_{i}}=g\left(P_{i}\right)
$$

Assuming (falsely) linear relationships for both Eqs. $1^{10}$ and 3 we get the following system of equations ${ }^{11}$ :

$$
\begin{aligned}
X_{m_{i}} & =P_{i} \beta+\epsilon_{i} \\
\left|Y_{i}-X_{m_{i}}\right| & =X_{i} \gamma+\theta_{i}
\end{aligned}
$$

Our theoretical models would lead us to expect a negative value for the component of $\gamma$ measuring the effect of direct legislation. Assuming further that $\epsilon_{i} \sim N\left(0, \sigma_{\epsilon}^{2}\right)$ and $\theta_{i} \sim$ $N\left(0, \sigma_{\theta}^{2}\right)^{12}$ we may use Eq. 4 to derive the following two equations:

\footnotetext{
8 It is interesting to note that exactly the same setup and discussions about the appropriate empirical models occurred in the literature on the representation and responsiveness of legislators to their constituencies' preferences (see especially Achen 1977). I will come back to this parallel later in this paper.

9 Again, this point is already made in Achen (1977) incisive critique of the literature on responsiveness.

10 The assumption that Eq. 3 is linear combined with a simplifying distributional assumption (see below) leads to a switching regression model discussed by Maddala (1983, p. 283, see also Maddala 1986).

${ }^{11}$ Hagen et al. (2001), in their response to Matsusaka (2001) critique of their approach suggest a very similar setup. They ignore, however, that even if the median voter's preferences could be directly measured, there would still be measurement error. In the presence of measurement error, as Achen (1977) clearly demonstrates in the related field of studies on representation and responsiveness, even a simple regression approach is not feasible in this context. It may help to illustrate this point by the strategy used by some scholars of representation. If both the voters' and legislators' preferences were measured without error (especially the former) we would expect under the assumption of perfect representation a slope coefficient of 1 . Any deviation from this value of the estimated slope coefficient would suggest less representation. This implies in the context of studies on the effect of direct legislation, that the estimated coefficient for an interaction effect between the presence of these institutions and the voters' preferences may be positive or negative and lead to less representation. Hence, this slope estimate provides no information on the question whether policy is more responsive in direct legislation states when used in a linear regression model. The empirical results reported below demonstrate this point.

12 These assumptions on the marginal distributions of the two error terms make the derived model equivalent to the switching regression model discussed by Maddala (1983, p. 283). As the results of the Monte-Carlo simulations suggest, both this simplifying assumption concerning the distribution of $\theta_{i}$ and the linearity assumption in Eq. 1 do not lead to significant biases in our inferences.
} 


$$
\begin{aligned}
& \text { if } Y_{i}-X_{m_{i}}>0, \quad Y_{i}=P_{i} \beta+X_{i} \gamma+\epsilon_{i}+\theta_{i} \\
& \text { if } Y_{i}-X_{m_{i}} \leq 0, \quad Y_{i}=P_{i} \beta-X_{i} \gamma+\epsilon_{i}-\theta_{i}
\end{aligned}
$$

This system of equation can be rewritten in such a way that it becomes a switching regression model with endogenous switching (Maddala 1983, p. 283), where the superscript for $Y$ indicates the regime ${ }^{13}$ :

$$
\begin{aligned}
Y_{i}^{1}= & P_{i} \beta+X_{i} \gamma+\epsilon_{i}+\theta_{i} \\
Y_{i}^{2}= & P_{i} \beta-X_{i} \gamma+\epsilon_{i}-\theta_{i} \\
I_{i}= & Y_{i}-P_{i} \beta-\epsilon_{i} \\
Y_{i}= & Y_{i}^{1} \text { if } I_{i}>0 \\
Y_{i}= & Y_{i}^{2} \text { if } I_{i} \leq 0 \\
& \left(\epsilon_{i}+\theta_{i}, \epsilon_{i}-\theta_{i},-\epsilon_{i}\right) \sim N(0, \Sigma)
\end{aligned}
$$

Here it becomes possible to compare the theoretically implied empirical model as specified by Eq. 6 with other empirical models used in the literature. ${ }^{14}$ First, one predominantly used model attempts to assess the effect of direct legislation with a simple dummy indicator in a linear regression model (see for instance Matsusaka 1995, 2000; Matsusaka 2004; Santoro and McGuire 1997; Kirchgässner et al. 1999; Santoro 1999). This traditionally used empirical model supposes that the effect of $X_{i}$, i.e. the policy bias in non-direct legislation, is always either positive or negative. If this is not the case, estimating a simple OLS model with a dichotomous indicator for direct legislation states yields estimates biased toward zero. Lascher et al. (1996) by adding in addition to the previous model an interaction between the direct legislation indicator and a preference measure probably attempted to allow for the conditional effect of preferences as specified in Eq. 6. The system of equation, however, suggests that the effect of preferences should not vary, but that the effect of the direct legislation dummy is contingent on preferences. Finally, Eq. 6 also shows that Pommerehne $(1978 \mathrm{a}, \mathrm{b})$ test based on the error variances between direct and non-direct legislation states is not accurate, since the variances differ in a more complex way between the two sets of states, except if we can assume that $\theta=0 .{ }^{15}$

While the system of Eq. 6 provides a close approximation of the theoretical models, a complication appears, however, in the estimation of the switching regression model since the switching indicator $I_{i}$ in Eq. 6 is not observed. More specifically, given that policy outcome $(Y)$ and preferences $(P)$ are measured in different scales, we do not observe whether a direct legislation state is in regime 1 or regime 2 (see Eq. 6). As Lee and Trost (1978) and Maddala (1983) show, the corresponding log-likelihood function (Eq. 8) is unbounded. In the original switching regression model with endogenous switching, three distinct error terms appear in the first three equations of the system of Eq. 6 (Maddala 1983, p. 283). Hence, the variancecovariance matrix in the original switching regression models contains six different terms. As Lee and Trost (1978) and Maddala (1983) demonstrate, not all six variance-covariance terms can be estimated, given that they are not identified. Hence, restrictions have to be imposed.

\footnotetext{
13 It has to be noted that the two regimes refer to whether in a state with direct legislation voters want more or less of a specific policy output than the legislator. Hence, implicitly there is a third regime corresponding to the states without direct legislation. I wish to thank Sven Feldmann for alerting me to this parallel and for catching a crucial error in a previous version of my argument. In the notation I follow as closely as possible Maddala (1983, p. 283) in order to make the parallels visible.

14 Bowler and Donovan (2004) also critically discuss some of these models.

15 See Romer and Rosenthal (1979) for a related critique.
} 
The derivation of the model from theoretical implications proposed here, however, leads only to two error terms, and thus three distinct terms in the variance-covariance matrix ${ }^{16}$ :

$$
\Sigma=\left[\begin{array}{ccc}
\sigma_{\epsilon}^{2}+\sigma_{\theta}^{2}+2 \sigma_{\epsilon, \theta} & \sigma_{\epsilon}^{2}-\sigma_{\theta}^{2} & -\sigma_{\epsilon}^{2}-\sigma_{\epsilon, \theta} \\
\sigma_{\epsilon}^{2}-\sigma_{\theta}^{2} & \sigma_{\epsilon}^{2}+\sigma_{\theta}^{2}-2 \sigma_{\epsilon, \theta} & -\sigma_{\epsilon}^{2}+\sigma_{\epsilon, \theta} \\
-\sigma_{\epsilon}^{2}-\sigma_{\epsilon, \theta} & -\sigma_{\epsilon}^{2}+\sigma_{\epsilon, \theta} & \sigma_{\epsilon}^{2}
\end{array}\right]
$$

Hence the theoretical model from which the switching regression model here is derived automatically leads to the restrictions on the variance-covariance matrix necessary to estimate all the parameters of interest. The likelihood function under the assumption of a normal bivariate distribution of the error terms $\epsilon$ and $\theta$ with mean 0 , variances $\sigma_{\epsilon}^{2}$ and $\sigma_{\theta}^{2}$ and covariance $\sigma_{\epsilon, \theta}$ (possibly 0 ) is the following ${ }^{17}$ :

$$
\begin{aligned}
\text { llik }= & \ln \Pi_{i}\left[F\left(Y_{i}-X_{m_{i}}, \sigma_{\epsilon_{i}}^{2}\right)\right. \\
& \times f_{N}\left(Y-P_{i} \beta-X_{i} \gamma, \sigma_{\epsilon+\theta}^{2} \mid Y_{i}-X_{m_{i}}>\epsilon_{i}\right) \\
& +\left(1-F\left(Y_{i}-X_{m_{i}}, \sigma_{\epsilon_{i}}^{2}\right)\right) \\
& \left.\times f_{N}\left(Y-P_{i} \beta+X_{i} \gamma, \sigma_{\epsilon-\theta}^{2} \mid Y_{i}-X_{m_{i}} \leq \epsilon_{i}\right)\right]
\end{aligned}
$$

The estimation through maximization of Eq. 8 is simplified by the fact that the variance-covariance matrix $\Sigma$ (Eq. 7) only contains three distinct elements, namely $\sigma_{\epsilon}^{2}, \sigma_{\theta}^{2}$ and $\sigma_{\epsilon, \theta} \cdot{ }^{18}$

\section{Monte Carlo simulations}

To assess the properties of the proposed switching regression model I carried out a series of Monte Carlo simulations. ${ }^{19}$ To generate the datasets I used two setups. The first one was designed to correspond as closely as possible to the empirical model, while the second one modeled the effect of direct legislation in a more challenging way. In the first setup the data were generated in the following way ${ }^{20}$ :

$$
\begin{aligned}
& P=5+2 * X_{1}+\epsilon \\
& Y=2+5 * P+\theta
\end{aligned}
$$

\footnotetext{
16 This variance-covariance matrix follows directly from the error terms appearing in Eq. 6 for $Y^{1}, Y^{2}$ and $D$.

17 I refrain from deriving in detail this likelihood function since, with the exception of the restrictions on the variance-covariance matrix it is equivalent to the models presented in Maddala (1983, p. 283) and Wilde (1998).

18 Wilde (1998) discusses this model in more detail and provides suggestions for the implementation of the estimation. The estimations carried out for this paper proved rather sensitive to the starting values employed. I systematically used the OLS-estimates as starting values for the estimation for a restricted version of the model, namely with the restrictions that $\sigma_{\theta}^{2}=\sigma_{\epsilon, \theta}=0$. The estimates for this model were then used as starting values for a model using as only restriction that $\sigma_{\epsilon, \theta}=0$. These estimates were then used as starting values for the unrestricted model.

19 These simulations have two main objectives. First, given that the proposed empirical model is based on a simplification, the simulations should show under what conditions this simplification still allows for correctly estimating the effect of direct legislation. Second, given that most studies assessing the effect of direct legislation rely on a small set of observations, the simulations should assess the small sample properties of the proposed estimator.

20 Strictly speaking in the second equation the values 2 and 5 could be dropped to correspond perfectly to the theoretical setup. I maintained these values to allow for additional policy biases.
} 
The independent variable $X_{1}$ was generated as a random draw from a uniform distribution over the unit-interval. To allow for correlation among the error terms $\epsilon$ and $\theta$ were constructed in the following way:

$$
\begin{aligned}
& \epsilon=(1-j) \times \alpha_{1}+j \times \alpha_{2} \\
& \theta=\left\{\begin{array}{cc}
\alpha_{2}+2 \times \alpha_{3} & \text { if } d l=0 \\
\alpha_{2}+1 \times \alpha_{3} & \text { if } d l=1
\end{array}\right.
\end{aligned}
$$

where $\alpha_{1}, \alpha_{2}$, and $\alpha_{3}$ are drawn from three independent normal distributions $N(0,1)$. If $j=0 \epsilon$ and $\theta$ are uncorrelated. Letting $j$ vary from 0 to 1 , induces increasing correlations in the error terms. In addition the proportion of states with direct legislation $(d l=1)$ was varied from 0 , to 0.25 and $0.5 .^{21}$

This setup obviously quite closely reflects the empirical model proposed. Hence, to carry out a more challenging test of the empirical model I also performed Monte Carlo simulations with a second setup. In this latter setup, the following relationships related the exogenous $X_{1}$ to preferences and policy outcome:

$$
\begin{aligned}
& P=5+2 * X_{1}+\epsilon \\
& Y=\left\{\begin{array}{l}
P+0+\theta \text { if } d l=1 \\
P+1+\theta \text { if } d l=0 \text { and } \alpha>p \\
P-1+\theta \text { if } d l=0 \text { and } \alpha \leq p
\end{array}\right.
\end{aligned}
$$

$\alpha$ is drawn from a uniform distribution over the unit-interval and $p$ was varied from 0 to 0.25 and 0.5 . In this setup policy deviates by 1 from the preferences of the voters either in a positive or a negative direction in non direct-legislation states. The value of $p$ determines the proportion of states for which the effect is in a negative direction. The frequently used model testing the effect of direct legislation by simply estimating the effect for a dichotomous indicator implicitly assumes that $p=0$ (or $p=1$ ). As $p$ diverges from these extreme values, the estimates from that traditional empirical model are biased toward zero. The structure of the error terms was set up in the same way as in the first setup. ${ }^{22}$

In both setups 1,000 samples for different sizes (i.e., 20, 50, 100, 200, ., 1000) were drawn. As Lee and Trost (1978), Maddala (1983) and Wilde (1998) note, however, the performance of this estimator is quite sensitive to starting values. In the Monte Carlo simulations this led to failures to reach convergence, especially in runs with small sample sizes. Consequently for some combinations of sample sizes, parameter values etc., only a small numbers of runs converged. Instead of playing around with starting values, ${ }^{23}$ I report the results for these runs as well, but by highlighting that they are based on smaller number of replications.

The first results depicted in the eleven panels of Fig. 1 are based on the first setup for the generation of the data. I report the mean estimate for the direct legislation coefficient

21 The dichotomous $d l$ variable was generated by using a draw from a uniform distribution over the unit interval. If the value drawn was below 0.5 (resp. $0.25,0$ ) the value of $d l$ was set to 0 , and to 1 else. I varied this parameter to assess whether the proposed model could also be estimated in a set of observations where very few units have direct legislation.

22 I compare in the Monte Carlo simulations only the proposed estimator here and the empirical model where the effect of direct legislation is estimated with a simple dichotomous estimator. The reason for this is that as I have discussed above, in the approach chosen by Lascher et al. (1996) and Camobreco (1998) there is no clear expectation what the "correct" estimate for the interaction between voter preferences and the direct legislation variable should be.

23 In the empirical illustrations provided in this paper it was clearly evident that when trying different starting values convergence was always obtained. 

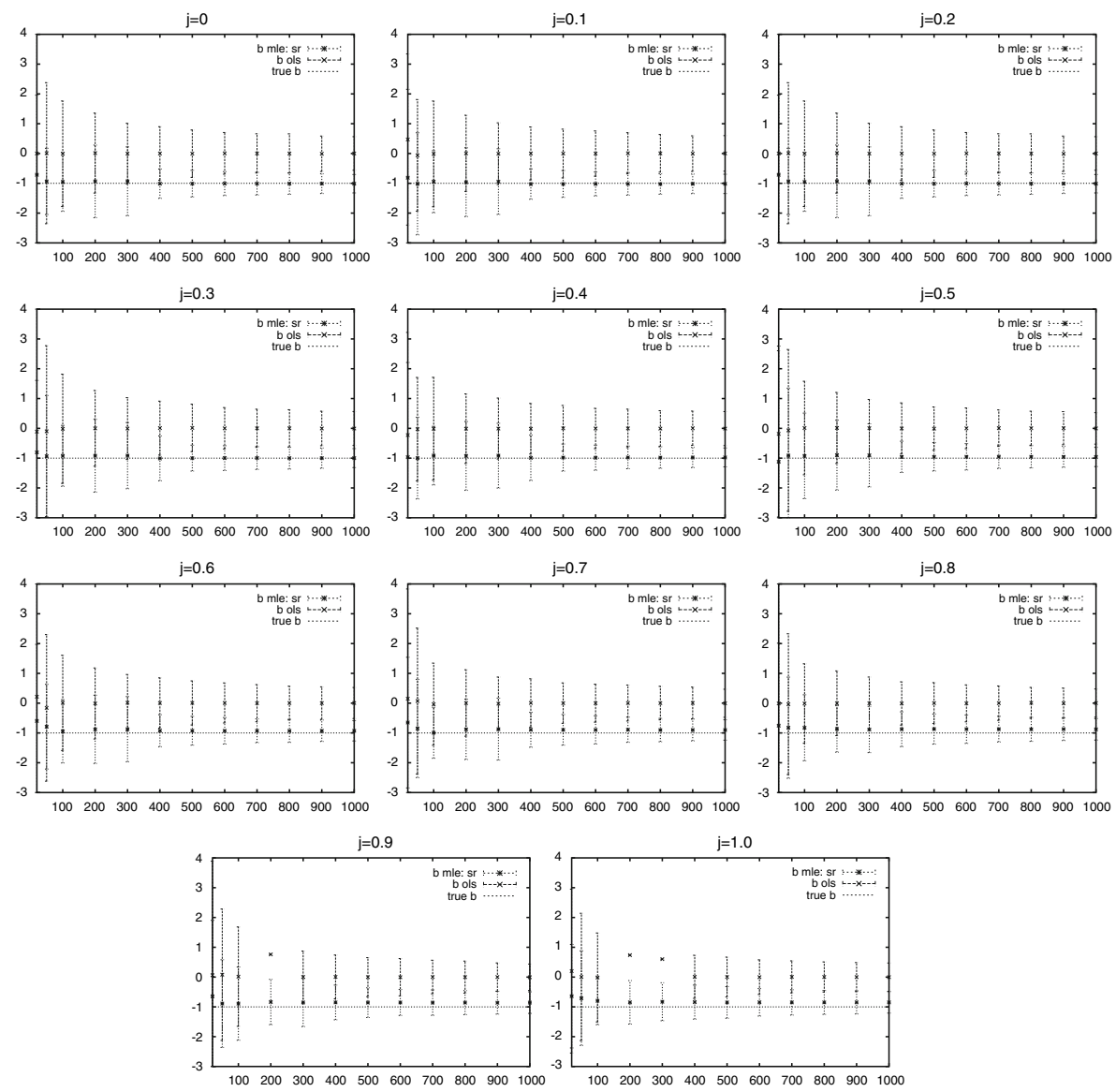

Fig. 1 Monte Carlo simulations based on variance specification

obtained from the switching regression (b mle sr) as well as the one obtained from a simple linear regression (b ols) as a function of the sample size. ${ }^{24}$ For each mean estimate I also report confidence intervals based on the distribution of the estimated coefficients. Finally, each panel corresponds to a different degree of correlation among the errors, going from values for $j$ from 0 to 1 (see Eq. 10).

The results depicted in Fig. 1 demonstrate essentially two things. First, the OLS estimate is on average zero and thus suggests that direct legislation has no impact on policy, while the estimate from the switching regression yields a mean estimate very close to the true value, namely -1 . Second, the confidence intervals around these mean estimates shrink quite quickly from their large values for small sample sizes when moving to larger samples. Only in the small samples do the confidence intervals around the mean estimate of the switching regression include the value 0 . Both of these results are largely unaffected by increasing

24 In all panels the mean estimated coefficients and confidence intervals are based on 1,000 runs, except for the smaller sample sizes of 300 or fewer observations. For these runs, on average a few hundred runs are at the basis of the results. The confidence intervals were approximated in all figures by $\bar{b} \pm 2 \times s_{b}$. 
the correlation between the error terms. ${ }^{25}$ Consequently, the switching regression estimates give on average unbiased estimates of the main quantity of interest, namely the coefficient for the direct legislation dummy. OLS regressions in this particular setup of the Monte Carlo simulations are unable to detect the effect of direct legislation, since the policy is not biased in the same direction in all states.

In the second setup, the switching regression model is more thoroughly tested by varying the degree to which policy is biased in the same direction in non-direct legislation states. In a first set of Monte Carlo simulations I set the proportion of non-direct legislation states to 0.5 , and in half of them policy is biased in a negative direction, and in half in a positive one. The size of this effect is equal to 1 again, however, given the way in which the data is generated, the coefficient from the switching regression depends on the variances of the other components.

For this reason I depict in Fig. 2 apart the confidence intervals for the OLS and switching regression result only a line at 0 , illustrating whether the estimates on average show a significant effect for direct legislation. ${ }^{26}$ As for the previous Monte Carlo simulations, the mean of the estimated OLS coefficients is approximately 0, independent of the size of the sample or the correlation in the error terms. In addition, the confidence intervals are again rather wide, implying that we would systematically reject the hypothesis that direct legislation has an effect on policy. The estimates from the switching regression model, on the other hand, are systematically negative and for almost all sample sizes the confidence intervals fail to include 0 . Only for small sample sizes, i.e. 20, 50, 100 and 200, is this not the case. $^{27}$

Again this setup of the Monte Carlo simulations indirectly played in favor of the switching regression model. Clearly if among the non-direct legislation states the policy bias goes more frequently in the same direction, the switching regression model will have a harder time detecting this effect. For this purpose I designed two further Monte Carlo simulations. In the first a quarter of the non-direct legislation states have a positive policy bias, while in the second this proportion drops to zero. ${ }^{28}$

Figure 3 reports the result for the simulations where a quarter of the non-direct legislation states have a positive policy bias. ${ }^{29}$ For small samples, neither the OLS nor the switching regression estimates are accurate. The confidence intervals for both estimators include the value of 0 . With sample sizes of 300 or more, largely independent of the correlation between the error terms, both estimators clearly indicate an effect for direct legislation. Interestingly, the sample sizes starting with which confidence intervals fail to include the value of 0 are largely the same, though with a small advantage for the OLS estimator. The advantage of the switching regression estimator, however, is that it gives clearly

\footnotetext{
25 Not surprisingly, the estimated coefficient for $P$ in Eq. 9 is affected by increasing correlation between the two error terms. The bias is, however, largely identical both in the OLS and switching regression estimates. For this reason I refrain from reporting these results here.

26 Again, problems of convergence with fixed starting values resulted in numbers of runs differing according to the combinations of parameter values. More specifically, only runs with small correlations between the error terms (i.e., $j \leq 0.6$ in Eq. 10) and sample sizes of at least 200 resulted in approximately 1,000 runs.

27 The wide confidence intervals are closely related to the sensitivity of the estimator to starting values. In the empirical examples discussed below, even with data with few observations, quite precise estimates could be obtained, when different starting values were employed.

28 This corresponds to setting $p$ in Eq. 10 to 0.25 , respectively 0 .

29 Again, the information depicted in the eleven panels is based on 1,000 runs only for small degrees of correlations in the error terms and sample sizes of at least 200. For all other combinations of parameter values the results from smaller number of runs are reported.
} 

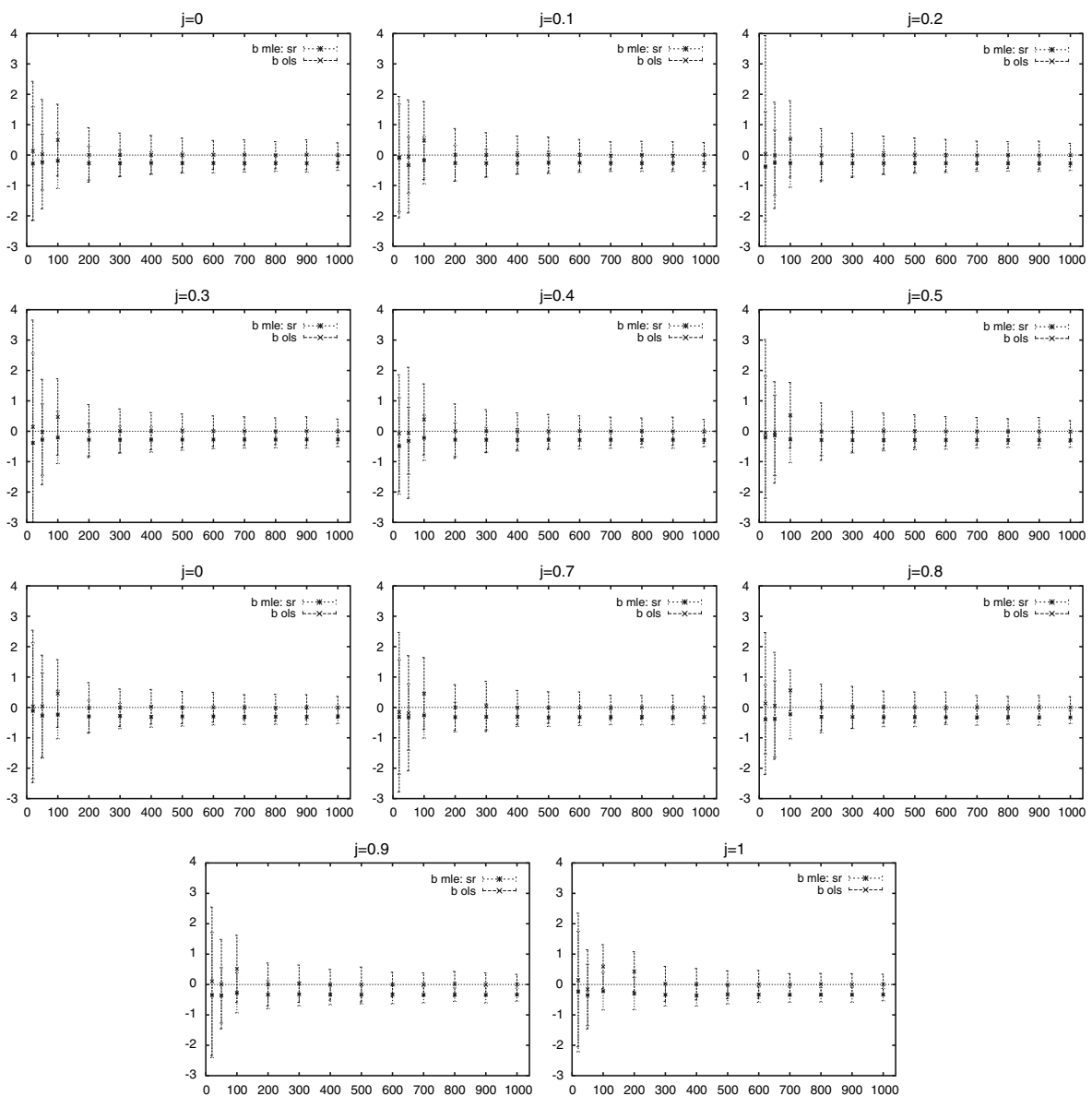

Fig. 2 Monte Carlo simulations based on dummy effect with $p=0.5$

support to the theoretically derived hypothesis, while the OLS estimator fails to yield this information.

Finally, when the bias to policy is in the same direction in all non-direct legislation states the results of the Monte Carlo simulations look as depicted in Fig. 4. Not surprisingly in this case the tables are turned for the OLS and the switching regression models. Since the policy bias goes in the same direction in all non-direct legislation states, the OLS model with a simple dummy variable is able to pick up this effect very well. Hence, the estimated coefficient is for all sample sizes and correlations of the error terms approximately equal to 1 . The confidence intervals with increasing sample sizes diminish quickly and exclude 0 for most parameter combinations. The switching regression model, however, yields mean estimates close to zero and also decreasing confidence intervals. The reason for this is obviously that in the data there is no hint whatsoever that biases may go in opposite directions. In the absence of such information, the switching regression model is unable to detect this difference.

The Monte Carlo simulations of the switching regression model compared to the simple OLS model clearly illustrated the strengths of the former. Provided that the policy biases 

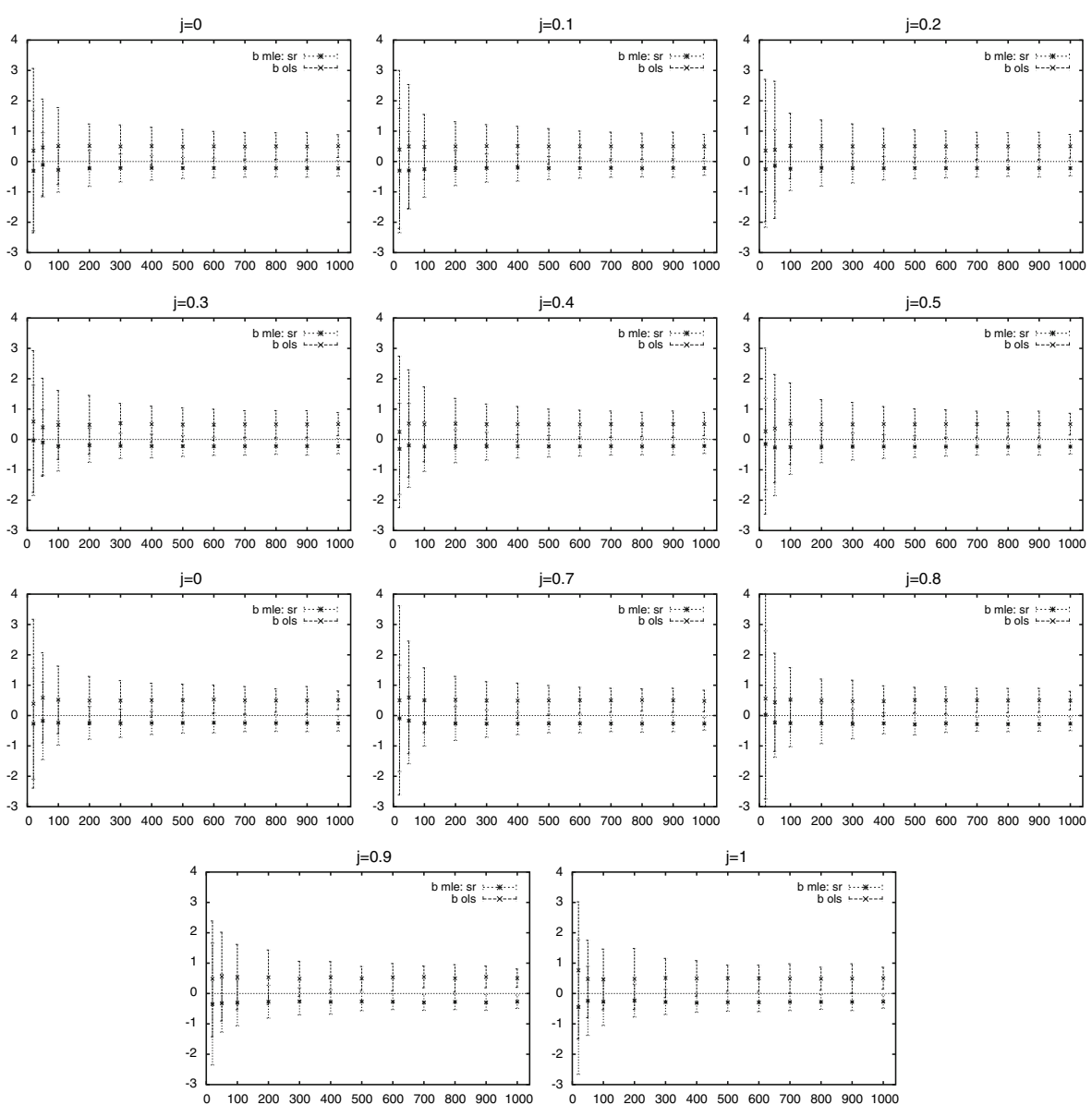

Fig. 3 Monte Carlo simulations based on dummy effect with $p=0.25$

in non-direct legislation states are not systematically in the same direction, the switching regression model gives us accurate estimates of the policy bias that direct legislation allows to correct for. Only when the policy bias in the non-direct legislation states is always or almost always in the same direction does the OLS model with a simple dichotomous indicator give us a better answer. While in such situations the OLS model is preferable, the estimates provided do not allow us to draw any conclusions on whether the correction of the policy bias due to direct legislation goes in the direction of the median voter or not. Only information external to the model, like for instance the information that Matsusaka (2000); Matsusaka (2004) has collected on contents of direct legislation proposals and other information allow us to gain some insights in the direction of the policy bias.

\section{Policy consequences of direct legislation}

While the Monte Carlo simulations already showed that the switching regression model yields more information on the effect of direct legislation and also provides better estimates 

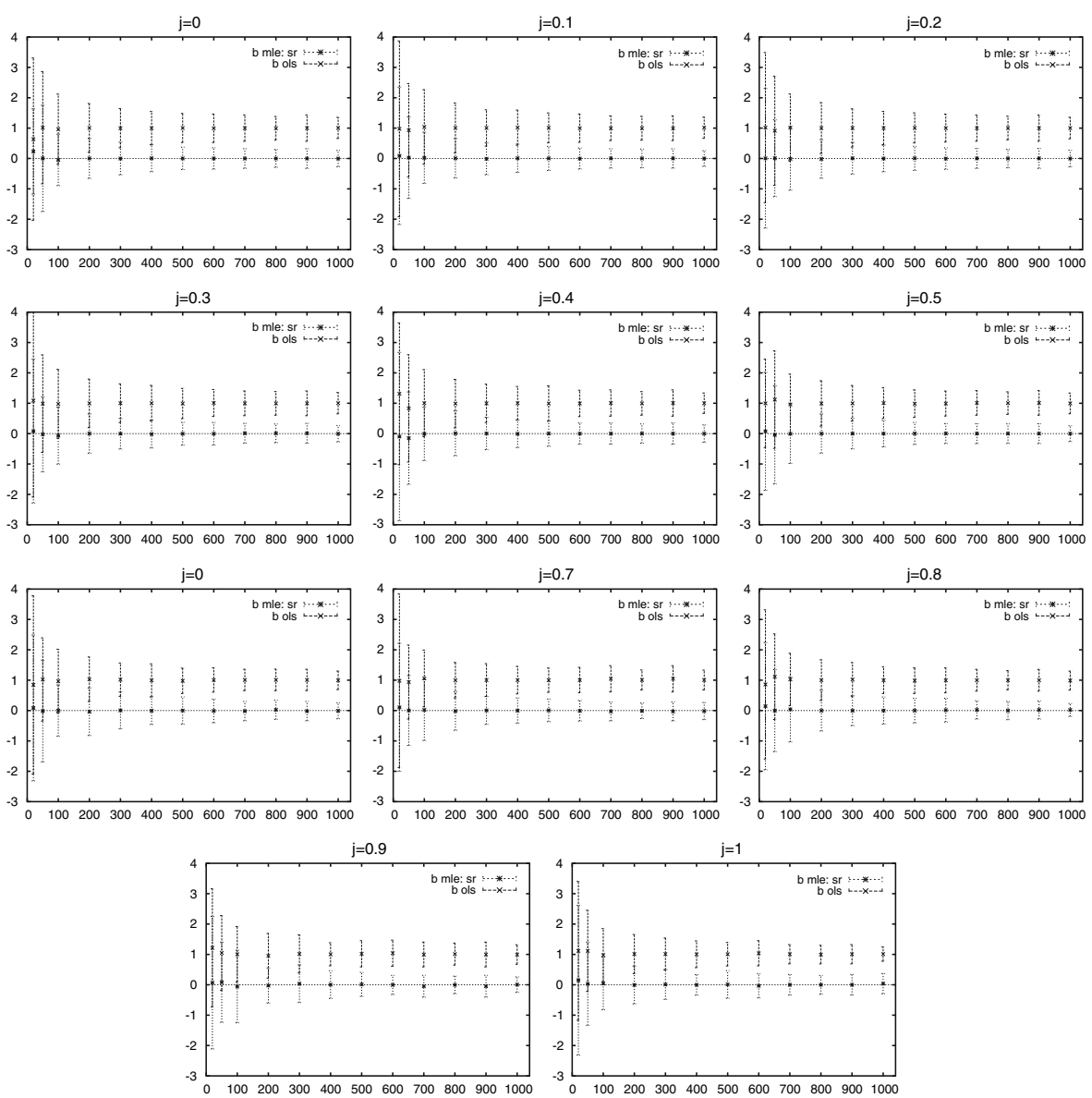

Fig. 4 Monte Carlo simulations based on dummy effect with $p=0$

except under very specific conditions, concrete examples may better illustrate the advantages of this estimator. To do so I use the data employed by Lascher et al. (1996) (see Table 1 for the policies employed ${ }^{30}$ ) to assess the effect of direct legislation in the US states. The basic specification (see Table 2) uses as independent variables the percentage of high school graduates, the state per capita income, the percent of urban residents and the ideology scale proposed by Erikson et al. (1993). Lascher et al. (1996) in addition use a dichotomous indicator for direct legislation and an interaction term between this variable and the ideology scale. As Matsusaka (2001) demonstrates, these authors erroneously interpret the coefficient

30 I refrained from using the policy of the Equal Rights Amendment (ERA) for these analyses. The variable used by Lascher et al. (1996) counts the number of years between the ratification of the ERA amendment and 1982 but equals 0 for all states not having ratified this amendment. Thus, this variable is censored and is clearly not appropriate as dependent variable in a linear regression framework. As a consequence I also do not use Lascher et al.'s (1996) summary index, which corresponds to the sum of the $z$-values of the eight policy measures. 
Table 1 Policies and their measurement

\begin{tabular}{ll}
\hline Variable & $\begin{array}{l}\text { Policy a } \\
\text { AFDC }\end{array}$ \\
$\begin{array}{l}\text { "scope of aid to families with } \\
\text { dependent children" } \\
\text { "enactment of various consumer } \\
\text { protection laws" } \\
\text { "use of different approaches } \\
\text { to criminal justice" }\end{array}$ \\
Educational expenditures & $\begin{array}{c}\text { "educational spending per pupil" } \\
\text { "extent to which legalized gambling } \\
\text { is allowed" }\end{array}$ \\
Tax policy & "tax progressivity" \\
Medicaid policy & "scope of the Medicaid program" \\
\hline
\end{tabular}

for this interaction term as evidence for the effect of direct legislation and essentially find no effect.

As in Lascher et al. (1996) these analyses only cover 47 states, since according to Erikson et al. (1993) the ideology measure for Nevada, Hawaii and Alaska is unreliable, and these states are thus omitted. ${ }^{31}$ I report in Table 2 for each of the seven selected policies first the result of a simple linear regression with a dichotomous indicator for direct legislation states $^{32}$ (columns OLS in Table 2). ${ }^{33}$ The estimates for this variable vary from positive to negative values and only for the policy of legalizing gambling is the estimated coefficient statistically significant. Consequently, based on this empirical model we would conclude that direct legislation only affects this particular policy in a statistically significant way.

If we estimate the switching regression model (column MLE in Table 2), ${ }^{34}$ we find for four out of the seven policies, namely AFDC, educational expenditures, gambling and Medicaid, negative coefficients for the direct legislation variable, as expected by the theoretical model. Three out of these four negative estimated coefficients are also statistically significant and thus provide clear support for the hypothesis that direct legislation biases policy toward the preferences of the voters. The three policies for which we find positive estimated coefficients are the consumer and the criminal justice policy, as well as tax progressivity. Among these three estimated coefficients, only the one for criminal justice policy reaches statistical significance. This result suggests that in direct legislation states policy outcomes

\footnotetext{
31 Hence, I use exactly the same data as Lascher et al. (1996), including their classification of states as having or not having direct legislation.

32 In analyses not reported here, I also used as additional independent variable a measure of the difficulty to qualify a direct legislation measure (i.e., signature requirement as a percentage of the voting population). Also the results for this additional independent variable yielded support for the empirical model proposed here, but to simplify the presentation I refrained from reporting these additional results here.

33 I fail to report the results reported in Lascher et al. (1996) since the estimates of their proposed model do not directly address the relevant theoretical implications. It suffices to say that these authors find for none of their policies studied the combination of estimated coefficients for the preference measure and the latter's interaction with a direct legislation indicator that they would take as evidence for increased policy responsiveness.

34 In the Appendix I also provide predicted probabilities for each state falling into regime 1 in the switching regression model (see Eq. 6).
} 


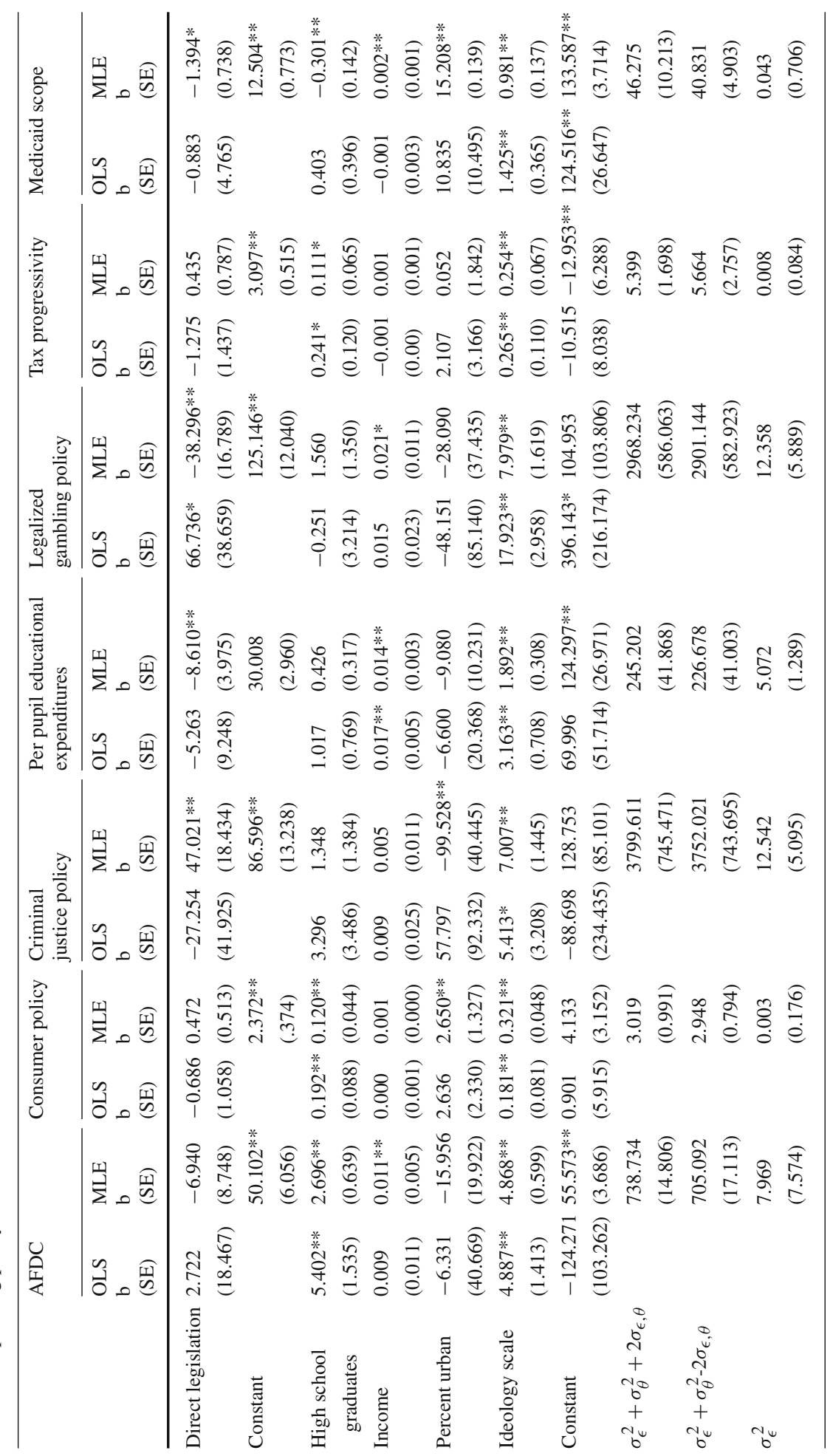




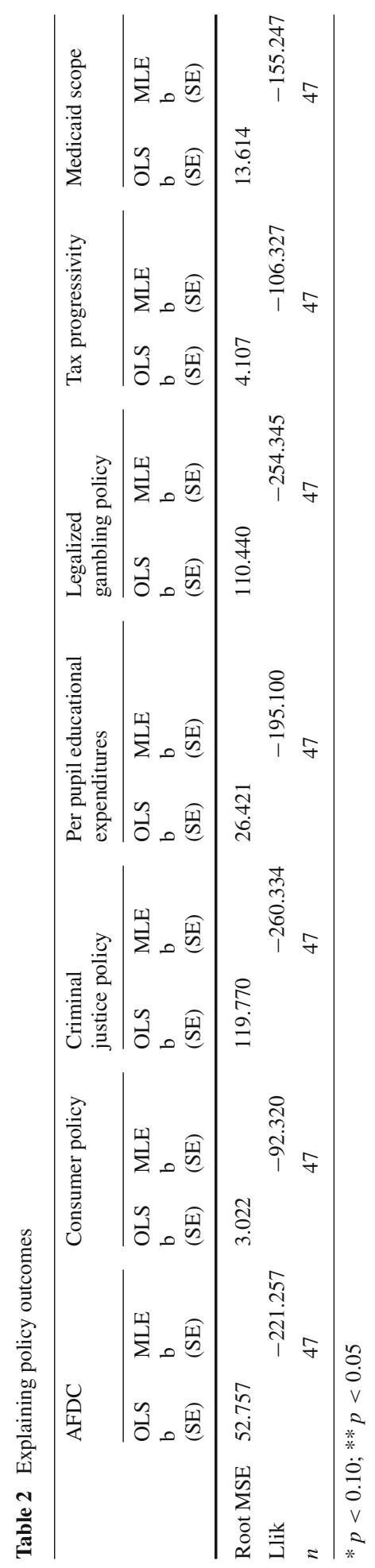


differ more strongly from the voters' wishes than in non-direct legislation states. Obviously this contradictory result is counterintuitive. Interestingly enough, however, it is exactly for this policy and the tax policy where the preference measures are most loosely related to policy outcomes. ${ }^{35}$ Hence, the negative results are more likely to be related to the rather poor proxies for the voters' preferences than to inherent problems with the proposed empirical model.

Nevertheless, the results reported in Table 2 demonstrate that the proposed switching regression model yields improved estimates for the effect of direct legislation. Contrary to the results presented by Lascher et al. (1996) we find for four of their policies effects for direct legislation as predicted by the theoretical models. A frequently used model, namely the one estimating a coefficient for a dichotomous direct legislation indicator, on the other hand, would suggest policy effects only for one of these policies. Hence, the switching regression model is a clear improvement over existing models to test for the effect of direct legislation. As the Monte Carlo simulations suggest, however, it should be used in conjunction with the traditional models.

\section{Discussion and conclusion}

In the current discussion of the merits and drawbacks of direct legislation both in the American states and around the world misguided generalizations often lead to erroneous statements about the effect of direct legislation. Systematic studies of the effect of direct legislation on policy outcomes (e.g., Matsusaka 1995, 2000; Matsusaka 2004; Gerber 1996, 1999; Gerber and Hug 1999; Kirchgässner et al. 1999; Besley and Case 2003; Feld and Matsusaka 2003) come to more nuanced conclusions than journalistic assessments (e.g., Schrag 1998; Broder 2000) or analyses relying on case studies (e.g. Smith 1998).

But even among the more systematic studies it has often proved elusive to find demonstrable effects of direct legislation on policy outcomes of the type we would expect from theory. In this paper I argued that the reason for this elusive quest is largely attributable to questionable empirical models. Based on the basic implication of most theoretical models, I derived an empirical model which improves on the models currently used by researchers trying to show that direct legislation has policy consequences. More precisely, this model directly acknowledges the fact that the effect of direct legislation is contingent on the preferences of at least the voters. Taking this into consideration in the empirical model I employed in this paper, I was able to show that results obtained by Lascher et al. (1996) are problematic and do not allow for the rejection of the theoretically derived hypothesis. More precisely, using their dataset and using both a simple empirical model testing for systematic policy biases in non-direct legislation states and the one proposed here, I demonstrated that the improved empirical model yields results largely in synch with theory and outperforms the simple model.

This empirical investigation, however, is hardly sufficient to demonstrate the merits of the empirical model proposed here. In Monte Carlo simulations I also demonstrated that under most conditions, the proposed switching regression model provides more accurate estimates than a simple OLS regression. Only under very specific conditions is the latter empirical model preferable. This suggests that both models should be used simultaneously in order to

\footnotetext{
35 This can easily be seen when comparing the root-mean squared error of the regressions and the descriptive statistics of the dependent variables provided in the Appendix.
} 
assess the effect of direct legislation. If a simple model with only a dummy indicator for the presence institutions for direct legislation yields a statistically significant coefficient, we can reject the null-hypothesis that direct legislation fails to affect policy outcomes. The size of the effect may, however, be biased toward zero and, in the absence of additional information, we cannot be sure that the bias is toward the median voter's preferences. ${ }^{36}$ If the effect of direct legislation is not significant, this may be due to the bias related to the empirical model or to a real absence of an effect. In both cases, however, estimating the proposed switching regression model would yield additional information. In the first case it might yield information on whether policy is biased toward the voters' preferences, while in the second it might show whether the null-result is due to the misspecified model or the real absence of an effect of direct legislation.

The use of the proposed empirical model is, however, not limited to assessing the effect of direct legislation. In very diverse research areas similar questions are raised and could be assessed with the same empirical model. Two areas may be most prominent for this. First, and most closely related to the topic of the present paper, the question whether in majoritarian political systems the preferences of the median voter are more closely reflected in government (see for a discussion Powell 2000) should lead to exactly the same empirical model. Second, the literature on the responsiveness and representativeness of legislators is quite clearly also dealing with the same effects. If we wish to assess the legislators' responsiveness on particular policies the model proposed here may yield improved insights. ${ }^{37}$ Hence, future research first of all on the effects of direct legislation, but also in other research areas should assess the applicability of the empirical model proposed here.

Acknowledgements Thanks are due to participants at these events and Chris Achen, Sven Feldmann, Mel Hinich, Tse-Min Lin, John Matsusaka, Phil Paolino, and George Tsebelis for enlightening discussions on the intricacies of the statistical issues in this paper, and Ted Lascher for sharing his dataset. Partial financial support by the Swiss National Science Foundation (Grants Nos. 8210-046545, 5004-0487882/1, and 100012-108179) is gratefully acknowledged. I assume responsibility for all remaining flaws and errors.

\section{Appendix}

Table 3 reports the descriptive statistics of the variables employed in this paper as well as their source. Table 4 reports the predicted probabilities for being in regime 1 in the switching regression models (see Eq. 6). ${ }^{38}$

\footnotetext{
${ }^{36}$ More specifically, when only estimating a model with a dummy indicator for direct legislation, extraneous information like in Matsusaka's $(2000,2004)$ study comparing the fiscal effects of direct legislation in two time periods has to be relied on to make arguments for the direction of these effects with regard to citizen preferences.

37 See Achen (1977) for a discussion of problems in this literature related to the issues discussed here. Bartels (1991) proposes a parallel way to address the problem discussed in this paper when studying the representativeness of legislators.

${ }^{38}$ I wish to thank Dan Woods for suggesting to report these probabilities.
} 
Table 3 Descriptive statistics

\begin{tabular}{|c|c|c|c|c|c|c|}
\hline Variable & Source & Min. & Mean & Max. & SD & $N$ \\
\hline Direct legislation & Dummy (Magleby 1984) & 0 & 0.45 & 1 & 0.50 & 47 \\
\hline Ideology scale & State ideology measure & -28 & -14.60 & -0.81 & 7.30 & 47 \\
\hline Income & Mean income 1980 & 6.68 & 9.01 & 11.54 & 1.17 & 47 \\
\hline High school graduates & Percent & 53 & 66.40 & 80 & 7.32 & 47 \\
\hline Percent urban & Percent of urban population & 0 & 0.53 & 0.93 & 0.25 & 47 \\
\hline AFDC & Lascher et al. (1996) & 87 & 241.36 & 400 & 83.45 & 47 \\
\hline Consumer policy & Lascher et al. (1996) & 4 & 13.57 & 21 & 3.85 & 47 \\
\hline Criminal justice policy & Lascher et al. (1996) & -100 & 153.19 & 400 & 131.63 & 47 \\
\hline Educational expenditures & Lascher et al. (1996) & 168 & 237.85 & 376 & 47.99 & 47 \\
\hline Legalized gambling policy & Lascher et al. (1996) & 0 & 257.45 & 600 & 171.62 & 47 \\
\hline Tax policy & Lascher et al. (1996) & -13 & -3.45 & 7 & 4.67 & 47 \\
\hline Medicaid policy & Lascher et al. (1996) & 100 & 125.94 & 159 & 17.70 & 47 \\
\hline
\end{tabular}

Table 4 Predicted probabilities for regime 1

\begin{tabular}{|c|c|c|c|c|c|c|c|}
\hline \multirow[t]{2}{*}{ State } & \multicolumn{7}{|c|}{ Policy $^{\mathrm{a}}$} \\
\hline & 1 & 2 & 3 & 4 & 5 & 6 & 7 \\
\hline Alabama & 0.00 & 1.00 & 1.00 & 0.00 & 0.00 & 0.00 & 0.00 \\
\hline Arizona & 0.00 & 0.00 & 0.00 & 0.03 & 1.00 & 0.00 & 0.00 \\
\hline Arkansas & 0.00 & 0.00 & 0.00 & 0.00 & 0.92 & 0.00 & 1.00 \\
\hline California & 1.00 & 1.00 & 1.00 & 0.00 & 0.00 & 1.00 & 1.00 \\
\hline Colorado & 0.00 & 0.00 & 1.00 & 0.04 & 0.00 & 0.00 & 0.00 \\
\hline Connecticut & 0.91 & 0.00 & 1.00 & 0.00 & 1.00 & 0.00 & 0.00 \\
\hline Delaware & 0.00 & 0.00 & 1.00 & 1.00 & 1.00 & 1.00 & 0.00 \\
\hline Florida & 0.00 & 1.00 & 1.00 & 0.00 & 1.00 & 0.00 & 0.00 \\
\hline Georgia & 0.00 & 0.00 & 1.00 & 0.00 & 0.00 & 1.00 & 0.00 \\
\hline Idaho & 1.00 & 1.00 & 0.00 & 0.00 & 0.00 & 1.00 & 0.00 \\
\hline Illinois & 0.05 & 0.00 & 1.00 & 0.13 & 1.00 & 0.00 & 0.00 \\
\hline Indiana & 0.00 & 0.00 & 0.86 & 0.00 & 0.00 & 1.00 & 0.00 \\
\hline Iowa & 1.00 & 0.00 & 1.00 & 0.00 & 0.00 & 1.00 & 0.00 \\
\hline Kansas & 0.02 & 0.00 & 1.00 & 0.00 & 0.00 & 0.00 & 1.00 \\
\hline Kentucky & 0.00 & 0.00 & 0.23 & 0.00 & 0.00 & 1.00 & 1.00 \\
\hline Louisiana & 0.00 & 1.00 & 0.00 & 0.00 & 0.99 & 1.00 & 0.00 \\
\hline Maine & 0.03 & 1.00 & 1.00 & 0.00 & 1.00 & 0.00 & 1.00 \\
\hline Maryland & 0.00 & 0.00 & 1.00 & 1.00 & 1.00 & 0.00 & 1.00 \\
\hline Massachusetts & 0.03 & 0.00 & 1.00 & 0.87 & 1.00 & 0.00 & 1.00 \\
\hline Michigan & 1.00 & 0.00 & 1.00 & 0.09 & 1.00 & 1.00 & 1.00 \\
\hline Minnesota & 1.00 & 0.00 & 1.00 & 0.74 & 0.00 & 1.00 & 1.00 \\
\hline Mississippi & 0.00 & 1.00 & 1.00 & 0.00 & 0.00 & 0.00 & 0.00 \\
\hline Missouri & 0.00 & 0.00 & 0.00 & 0.00 & 0.00 & 1.00 & 0.00 \\
\hline Montana & 0.00 & 0.00 & 0.99 & 1.00 & 1.00 & 0.00 & 1.00 \\
\hline
\end{tabular}


Table 4 continued

\begin{tabular}{|c|c|c|c|c|c|c|c|}
\hline \multirow[t]{2}{*}{ State } & \multicolumn{7}{|c|}{ Policy ${ }^{\mathrm{a}}$} \\
\hline & 1 & 2 & 3 & 4 & 5 & 6 & 7 \\
\hline Nebraska & 0.89 & 1.00 & 1.00 & 0.22 & 0.00 & 1.00 & 1.00 \\
\hline New Hampshire & 0.01 & 0.00 & 0.00 & 0.00 & 1.00 & 0.00 & 0.00 \\
\hline New Jersey & 0.00 & 0.00 & 0.98 & 1.00 & 1.00 & 0.00 & 0.00 \\
\hline New Mexico & 0.00 & 0.00 & 0.00 & 0.00 & 0.00 & 0.00 & 0.00 \\
\hline New York & 1.00 & 0.00 & 1.00 & 1.00 & 1.00 & 1.00 & 1.00 \\
\hline North Carolina & 0.01 & 1.00 & 1.00 & 0.00 & 0.00 & 1.00 & 0.00 \\
\hline North Dakota & 1.00 & 0.00 & 1.00 & 0.00 & 0.00 & 1.00 & 0.00 \\
\hline Ohio & 0.00 & 0.00 & 1.00 & 0.00 & 1.00 & 1.00 & 0.00 \\
\hline Oklahoma & 1.00 & 0.00 & 1.00 & 0.11 & 0.00 & 1.00 & 0.00 \\
\hline Oregon & 1.00 & 1.00 & 1.00 & 1.00 & 1.00 & 1.00 & 0.00 \\
\hline Pennsylvania & 1.00 & 0.00 & 1.00 & 1.00 & 1.00 & 1.00 & 1.00 \\
\hline Rhode Island & 1.00 & 0.00 & 0.00 & 1.00 & 1.00 & 0.00 & 0.00 \\
\hline South Carolina & 0.00 & 0.00 & 0.00 & 0.00 & 0.00 & 1.00 & 0.00 \\
\hline South Dakota & 0.84 & 1.00 & 0.00 & 0.00 & 1.00 & 0.00 & 0.00 \\
\hline Tennessee & 0.00 & 0.00 & 0.93 & 0.00 & 0.00 & 0.00 & 0.00 \\
\hline Texas & 0.00 & 1.00 & 1.00 & 0.00 & 0.00 & 0.00 & 0.00 \\
\hline Utah & 1.00 & 1.00 & 1.00 & 0.00 & 0.00 & 1.00 & 1.00 \\
\hline Vermont & 1.00 & 1.00 & 0.00 & 0.02 & 1.00 & 0.00 & 1.00 \\
\hline Virginia & 0.00 & 1.00 & 0.98 & 0.00 & 0.00 & 0.00 & 0.00 \\
\hline Washington & 0.98 & 0.00 & 0.00 & 0.00 & 0.99 & 0.00 & 1.00 \\
\hline West Virginia & 0.00 & 0.00 & 1.00 & 0.00 & 1.00 & 0.00 & 1.00 \\
\hline Wisconsin & 1.00 & 1.00 & 1.00 & 0.99 & 0.00 & 1.00 & 1.00 \\
\hline Wyoming & 0.00 & 0.00 & 0.00 & 0.99 & 0.00 & 0.00 & 0.00 \\
\hline
\end{tabular}

a 1 AFDC, 2 consumer policies, 3 criminal justice, 4 school expenditure per pupil, 5 Gambling, 6 tax policy, 7 Medicaid

\section{References}

Achen, C.H.: Measuring representation: perils of the correlation coefficient. Am. J. Polit. Sci. 21(4), 805815 (1977)

Bartels, L.M.: Constituency opinion and congressional policy making: the Reagan defense buildup. Am. Polit. Sci. Rev. 85(2), 457-474 (1991)

Besley, T., Case, A.: Political institutions and policy choices: evidence from the United States. J. Econ. Lit. 41(1), 7-74 (2003)

Besley, T., Coate, S.: Issue unbundling via citizens' initiatives. Paper prepared for presentation at the annual meeting of the Public Choice Society, San Antonio, 9-12 March 2001

Bowler, S., Donovan, T.: Measuring the effects of direct democracy on state policy and politics. State Polit. Policy Q. 4(3), 345-363 (2004)

Broder, D.S.: Democracy Derailed. Initiative Campaigns and the Power of Money. James H. Silberman Book/Harcourt, New York (2000)

Camobreco, J.F.: Preferences, fiscal policies, and the initiative process. J. Polit. 60(3), 819-829 (1998)

Cronin, T.E.: Direct Democracy. The Politics of Initiative, Referendum and Recall. Harvard University Press, Cambridge (1989)

Erikson, R.S., Wright, G.C., McIver, J.P.: Statehouse Democracy: Public Opinion and Policy in the American States. Cambridge University Press, New York (1993) 
Feld, L.P., Matsusaka, J.G.: Budget referendums and government spending: evidence from Swiss cantons. J. Public Econ. 87, 2703-2724 (2003)

Gerber, E.R.: Legislative response to the threat of popular initiatives. Am. J. Polit. Sci. 40(1), 99-128 (1996)

Gerber, E.R.: The Populist Paradox: Interest Group Influence and the Promise of Direct Legislation. Princeton University Press, Princeton (1999)

Gerber, E.R., Hug, S.: Minority Rights and Direct Legislation. Theory, Methods, and Evidence. Department of Political Science, University of California, La Jolla (1999)

Gerber, E.R., Hug, S.: Legislative responses to direct legislation. In: Mendelsohn, M., Parkin, A. (eds.) Referendum Democracy. Citizens, Elites, and Deliberation in Referendum Campaigns, pp. 88-108. Palgrave, New York (2001)

Hagen, M.G., Lascher, E.L., Camobreco, J.F.: Response to Matsusaka: estimating the effect of ballot initiatives on policy responsiveness. J. Polit. 63(4), 1257-1263 (2001)

Hug, S.: Occurrence and policy consequences of referendums. A theoretical model and empirical evidence. J. Theor. Polit. 16(3), 321-356 (2004)

Hug, S., Tsebelis, G.: Veto players and referendums around the world. J. Theor. Polit. 14(4), 465-516 (2002)

Key, V.O. Jr., Crouch, W.W.: The Initiative and the Referendum in California. University of California Press, Berkeley (1939)

Kirchgässner, G., Feld, L.P., Savioz, M.R.: Die direkte Demokratie der Schweiz: Modern, erfolgreich, entwicklungs- und exportfähig. Helbing und Lichtenhahn, Basel (1999)

Lascher, E.L., Hagen, M.G., Rochlin, S.A.: Gun behind the door-ballot initiatives, state policies and public opinion. J. Polit. 58(3), 760-775 (1996)

Lee, L.F., Trost, R.P.: Estimation of some limited dependent variable models with applications to housing demand. J. Econom. 8, 357-382 (1978)

Lupia, A., Matsusaka, J.G.: Direct democracy: new approaches to old questions. Annu. Rev. Polit. Sci. 7, 463482 (2004)

Maddala, G.S.: Limited Dependent and Qualitative Variables in Econometrics. Cambridge University Press, Cambridge (1983)

Maddala, G.S.: Disequilibrium, self-selection, and switching models. In: Griliches, Z., Intriligator, M.D. (eds.) Handbook of Econometrics, vol. III, pp. 1633-1688. Elsevier, Amsterdam (1986)

Magleby, D.E.: Direct Legislation: Voting on Ballot Propositions in the United States. Johns Hopkins University Press, Baltimore (1984)

Matsusaka, J.G.: Fiscal effects of the voter initiative: evidence from the last 30 years. J. Polit. Econ. 103(3), 587-623 (1995)

Matsusaka, J.G.: Fiscal effects of the voter initiative in the first half of the twentieth century. J. Law Econ. 43(2), 619-644 (2000)

Matsusaka, J.G.: Problems with a methodology used to test whether policy is more or less responsive to public opinion in States with voter intiatives. J. Polit. 63(4), 1250-1256 (2001)

Matsusaka, J.G.: For the Many or the Few. How the Initiative Process Chances American Government. University of Chicago Press, Chicago (2004)

Matsusaka, J.G., McCarty, N.M.: Political resource allocation: the benefits and costs of voter initiatives. J. Law Econ. Organ. 17, 413-448 (2001)

Moser, P.: Why is Swiss politics so stable?. Zeitschrift für Volkswirtschaft Und Statistik 132(1), 31-60 (1996)

Pommerehne, W.W.: Institutional approaches to public expenditure: empirical evidence from Swiss municipalities. J. Public Econ. 9, 255-280 (1978a)

Pommerehne, W.W.: Politisch-ökonomisches Modell der direkten and repräsentativen Demokratie. In: Helmstädter, E. (ed.) Neuere Entwicklungen in der Wirtschaftswissenschaft, pp. 569-589. Duncker und Humblot, Berlin (1978b)

Powell, G.B.: Elections as Instruments of Democracy. Majoritarian and Proportional Visions. Yale University Press, New Haven (2000)

Romer, T., Rosenthal, H.: The elusive median voter. J. Public Econ. 12, 143-170 (1979)

Santoro, W.A.: Conventional politics takes center stage: the Latino struggle against English-only laws. Soc. Forces 77(2), 887-909 (1999)

Santoro, W.A., McGuire, G.M.: Social movement insiders: the impact of institutional activists on affirmative action and comparable worth policies. Soc. Probl. 44(4), 503-519 (1997)

Schrag, P.: Paradise Lost: California's Experience, America's Future. New Press, New York (1998)

Smith, D.A.: Tax Crusaders and the Politics of Direct Democracy. Routledge, New York (1998)

Steunenberg, B.: Referendum, initiative, and veto power. Kyklos 45(4), 501-529 (1992)

Tsebelis, G.: Veto players in political analysis. Governance 13(3), 441-474 (2000)

Wilde, P.E.: The monthly food stamp cycle: shopping frequency and food intake decisions in an endogenous switching regression framework. PhD dissertation, Cornell University, Ithaca (1998) 